Molecules 2003, 8, 318-321

molecules

ISSN 1420-3049

http://www.mdpi.org

\title{
Modified Methods for the Synthesis of Triazinyl Fluorescent Brightener Intermediates
}

\author{
Javad Safaei-Ghomi ${ }^{1}$, ,, Mahmood Tajbakhsh ${ }^{2}$, Abdolhamid Bamoniri ${ }^{1}$ and Ali Parach ${ }^{1}$ \\ ${ }^{1}$ Department of Chemistry, Faculty of Sciences, University of Kashan, 51167 Kashan, I. R. Iran, \\ Fax: (+98) 361552930 . \\ ${ }^{2}$ Department of Chemistry, Faculty of Sciences, University of Mazandaran, Babolsar, I. R. Iran, \\ Fax: (+98) 1125242029.
}

*Author to whom correspondence should be addressed; E-mail: $\underline{\text { safaei@,kashanu.ac.ir }}$

Received: 18 August 2003; in revised form: 16 February 2003 / Accepted: 12 March 2003 / Published: 31 March 2003

\begin{abstract}
The production of triazinyl fluorescent brightener intermediates in high yields is described. The method involves a simplified work-up for the preparation of 4-nitrotoluene-2-sulfonic acid and the use of diethylene glycol instead of water in the preparation of 4,4'-dinitrostilbene-2,2'-disulfonic acid.
\end{abstract}

Keywords: Triazinyl Fluorescent Brighteners; Sulfonation; Direct Separation.

\section{Introduction}

4-Nitrotoluene-2-sulfonic acid (2) and 4,4'-dinitrostilbene-2,2'-disulfonic acid (3) are the key intermediates for the synthesis of triazinyl fluorescent brighteners [1]. Although there are many reports of preparations of these compounds, they all have problems in the work-up of compound 2 and they also report low yields and long reaction times in the preparation of 4,4'-dinitrostilbene-2,2'-disulfonic acid (3) [2-8]. Herein we report a modification of the common procedures to produce compounds 2 and $\mathbf{3}$ which involves simple work-ups, short reaction times and also affords high product yields. 


\section{Results and Discussion}

In the common procedures for the separation of $\mathbf{2}$ after the sulfonation of 4-nitrotoluene (1) (Scheme 1), compound $\mathbf{2}$ is converted into the corresponding salt. Subsequently it is extracted from the reaction mixture and ultimately the salt is acidified [2-4]. These methods involve many steps for the work-up of the product. This problem was solved by the use of a mixture of acetone-benzene as the solvent for the direct separation of product. In this alternative method the product was crystallized directly from the sulfonation mixture using that solvent system. The advantages of this method are the fewer separation steps and the high yield (96\%) \{lit[2] yield 95-96\% $\}$.

\section{Scheme 1}

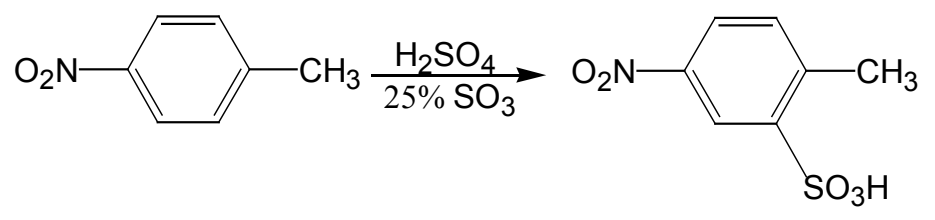

1

2

Previous methods for the self-oxidation of $\mathbf{2}$ by sodium hypochlorite (Scheme 2) in aqueous solutions suffer from low yields and long reaction times [5-8]. By the use of diethylene glycol instead of water in this reaction we both increased the yield (from 86 to 93\%) and reduced the reaction time.

\section{Scheme 2}

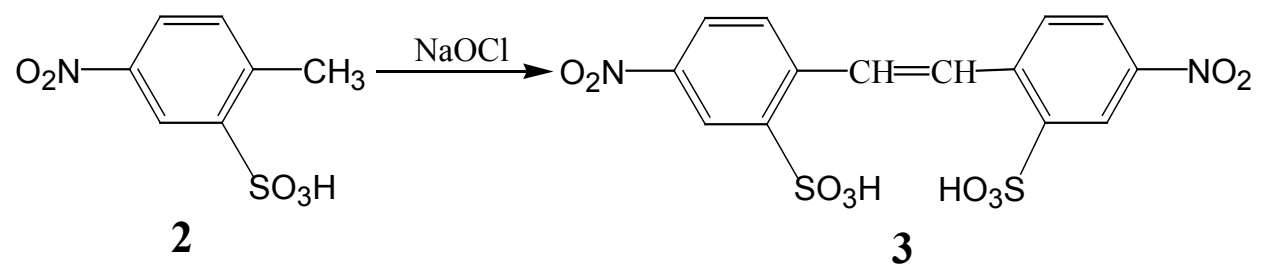

The above intermediate $\mathbf{3}$ can be converted into the triazinyl fluorescent brighteners $\mathbf{6}$ through the reduction of nitro groups to give 4, subsequent reaction with cyanuric chloride (5) and amines or alcohols (Scheme 3) [9,10].

\section{Conclusions}

A convenient method has been developed for the synthesis of 4-nitrotoluene-2-sulfonic acid and 4,4'-dinitrostilbene-2,2'-disulfonic acid as fluorescent brightener intermediates. Simple and clean workups, high yields and also short reaction times make this procedure an attractive method for the possible commercial synthesis of these products. 
Scheme 3

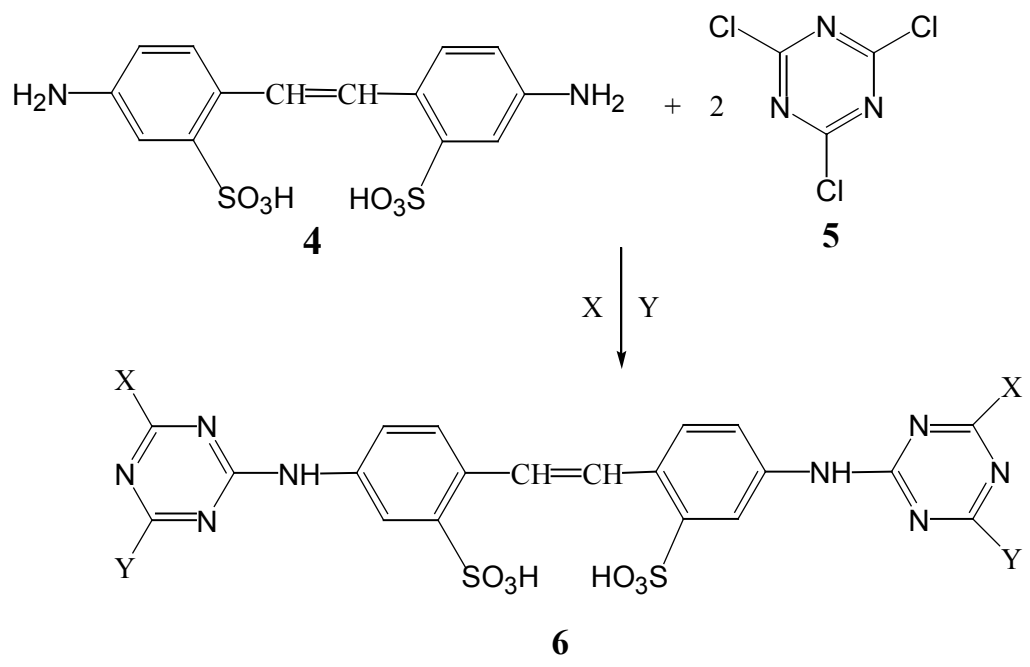

$\mathrm{X}$ and $\mathrm{Y}$ : amines or alcohols

\section{Acknowledgments}

The authors gratefully acknowledge partial support of this work by the Research Affairs Office of The University of Kashan, Kashan, Iran. They also thank Mr. M. R. Halvagar for his help in submitting this paper.

\section{Experimental}

\section{General}

Chemicals were purchased from the Fluka and Merck chemical companies. Melting points were taken on a Gallenkamp melting point apparatus and are uncorrected. ${ }^{1} \mathrm{H}-\mathrm{NMR}$ spectra were obtained at $250 \mathrm{MHz}$ using a Bruker Avance $250 \mathrm{NMR}$ in DMSO- $\mathrm{d}_{6}$ as the solvent. Mass spectra were obtained using a Finnigan Mat 8430 Mass spectrometer. The infrared spectra were determined on a Nicolet Magna series FTIR 550 spectrometer using $\mathrm{KBr}$ pellets. Thin layer chromatography (TLC) on commercial aluminium-backed plates of silica gel $60 \mathrm{~F}_{254}$ was used to monitor the progress of the reactions.

Simplified method for the preparation of 4-nitrotoluene-2-sulfonic acid (2).

4-Nitrotoluene $(13.7 \mathrm{~g}, 0.1 \mathrm{~mol})$ was melted at $55^{\circ} \mathrm{C}$ and stirred in a $100 \mathrm{~mL}$ round-bottom flask during the dropwise addition of $24 \%$ oleum $(21 \mathrm{~mL}, 0.4 \mathrm{~mol})$. The temperature was then raised to $75^{\circ} \mathrm{C}$ and stirring was continued at this temperature for one hour. When the sulfonation was complete (checked by TLC), the mixture was cooled and slowly added to water $(50 \mathrm{~mL})$ until the solid precipitated. The product (2) was filtered off and recrystallised from acetone-benzene (2:1) to give a 
cream colored solid melting at $133^{\circ} \mathrm{C}$ \{lit. [2] mp $\left.132-133^{\circ} \mathrm{C}\right\}$. yield: $19.0 \mathrm{~g}(96 \%) ;{ }^{1} \mathrm{H}-\mathrm{NMR} \delta(\mathrm{ppm})$ : $2.7(\mathrm{~s} ; 3 \mathrm{H}) ; 7.5(\mathrm{~d} ; 1 \mathrm{H}) ; 8.1(\mathrm{~d} ; 1 \mathrm{H}) ; 8.5(\mathrm{~s} ; 1 \mathrm{H})$. MS (EI): m/z: $217\left(\mathrm{M}^{+}\right) ; 200 ; 182 ; 135 ; 105 ; 89 ; 30$.

Preparation of 4,4'-dinitrostilbene-2,2'-disulfonic acid (3) using diethylene glycol as the solvent.

A mixture of sodium hypochlorite $(50 \mathrm{~mL}, 5 \%$ available chlorine) and a solution of sodium hydroxide $(6 \mathrm{~g})$ in water $(8 \mathrm{~mL})$ was slowly added with stirring to a warm $\left(40-45^{\circ} \mathrm{C}\right)$ solution of compound $2(5 \mathrm{~g})$ in diethylene glycol $(30 \mathrm{~mL})$. Stirring was continued and the temperature raised to $85^{\circ} \mathrm{C}$. After about ten minutes the reaction was complete (as indicated by starch-iodide paper). Upon cooling and filtration the sodium salt of 4,4'-dinitrostilbene-2,2'-disulfonic acid (5.6 g) was obtained. Treatment of this salt with hydrochloric acid afforded the free acid $3\left(5.1 \mathrm{~g}, 93 \%\right.$ yield), m.p. $266^{\circ} \mathrm{C}$ (lit. [6] m.p. $\left.266^{\circ} \mathrm{C}\right) ;{ }^{1} \mathrm{H}-\mathrm{NMR} \delta(\mathrm{ppm}): 7.9(\mathrm{~d} ; 1 \mathrm{H}) ; 8.3(\mathrm{~d} ; 1 \mathrm{H}) ; 8.4(\mathrm{~s} ; 2 \mathrm{H}) ; 8.6(\mathrm{~s} ; 1 \mathrm{H}) ;$ FTIR $\left(\mathrm{cm}^{-1}\right)$ : 2800, 3400, 1475, 1590, 1350, 1520, 1140, 1200; MS (EI): m/z: $430\left(\mathrm{M}^{+}\right) ; 349 ; 214 ; 165 ; 75$.

\section{References}

1. Venkatraman K. The Chemistry of Synthetic Dyes, Academic Press: New York, 1952; Vol. 1, pp. 628-629.

2. Lee J.G. et al, Process for the Production of p-Nitrotoluene-2-sulfonic Acid, U. S. Pat. 3840591, 1974.

3. Furniss B.S.; Hannaford, A.J.; Smith, P.W.G.; Tetcheu, A. R. Vogel's Textbook of Practical Organic Chemistry; $5^{\text {th }}$ Ed. Longman Scientific \& Technical: UK, 1991.

4. Bermes, R. et al, Preparation of Amine Salts of 4-Nitrotoluene-2-sulfonic Acid, U. S. Pat. 5892105, 1999.

5. Inukai K.; Maki Y., Fluorescent Bleaching Agent of Stilbene Series, I. Influence of Alkali and Sodium Hypochlorite in the Preparation of Dinitrostilbenedisulfonic Acid, Repts. Govt. Ind. Res. Inst., Nagoya, 1952, 1, 98-100, [Chem. Abstr. 1956, 50, 3347].

6. Kmonickova S.; Drabek J.; Cermak. J.; Mudroch J. Method of preparation of the 4, 4'Dinitrostilbene-2,2'-disulpho Acid, C. S. Pat. 216126, 1984. [Chem. Abstr. 1985, 102, 5933].

7. Bulliger H.R.; McGilvary J.R.N.; Smith, G., Process for the Industrial Manufacture of Dinitrostilbene Disulphonic Acid, G. B. Pat. 1381730, 1975.

8. Hein, D.W.; Pierce, E.S. Optical Bleaching Agents. I. Derivatives of Dichlorodiaminostilbene disulfonic Acid, J. Am. Chem. Soc., 1954, 76, 2725-2731.

9. Farris, R.E. In Kirk-Othmer, Encyclopedia of Chemical Technology, Wiley-Interscience: New York, 1983; Vol. 21, pp. 729-746.

10. Baker R.L. Fluorescent Whitening Agents, Its Preparation and Use, U. S. Pat. 6165973, 2000.

Sample Availability: Samples of compounds $\mathbf{2}$ and $\mathbf{3}$ are available from the authors.

(C) 2003 by MDPI (http://www.mdpi.org). Reproduction is permitted for non commercial purposes. 